\title{
Relation between Corrosion Inhibition Efficiency of Polar Organic Compounds for Some Non- transition Metals and the HSAB Principle
}

\author{
Kunitsugu Aramaki* \\ *Faculty of Science and Technology, Keio University
}

\begin{abstract}
The hard and soft acids and bases principle (HSAB principle) is closely related to an ability of chemical adsorption of polar organic inhibitors on metallic surface. Inhibition efficiency of the organic inhibitors for various transition metals in an acid solution is thus correlated with the principle. In this study, the inhibition efficiency of polar organic inhibitors was determined on non-transition metals, $\mathrm{Mg}, \mathrm{Al}, \mathrm{In}$, and $\mathrm{Sn}$ in $\mathrm{HClO}_{4}$ solutions at $30^{\circ} \mathrm{C}$ by polarization measurements. The inhibitors used were compounds in which elements of the polar atoms belong to the $4 \mathrm{~B}, 6 \mathrm{~B}$, and 7B groups in the periodic table. The relationship between the efficiency and the HSAB principle was confirmed to be established for the non-transition metals, though some disorders of the relationship were observed for $\mathrm{Mg}$ and $\mathrm{Al}$. An acid softness of the metals was estimated by using this relationship. The softness was increased in the order of $\mathrm{Mg}<\mathrm{Al}<\mathrm{In}<\mathrm{Sn}$. The inhibition efficiency of $\mathrm{Si}, \mathrm{Ge}$, and $\mathrm{Sn}$ compounds suggested the formation of adsorption bond by back-coordination of the metal electrons to an empty d-orbital of the polar atom.
\end{abstract}

\section{Introduction}

Most of polar organic compounds are chemically adsorbed on metallic surface by the formation of coordinate bond between their polar atoms and the metals.

$$
\mathrm{RX}:+\mathrm{M} \longrightarrow \mathrm{RX}: \mathrm{M}
$$

The adsorbed molecule inhibits the corrosion of the metal. Since the polar compound, acting as a corrosion inhibitor, is equivalent to Lewis base and the metal to Lewis acid, respectively, stability of the acid-base complex is closely related to the hard and soft acids and bases principle (HSAB principle) ${ }^{1)}$. Inhibition efficiency of the inhibitor thus relates to this principle.

As for the compounds of which polar atoms are of the $6 \mathrm{~B}$ and $7 \mathrm{~B}$ group elements in the periodic table, it has been reported that relation between the efficiency and the HSAB principle is valid for various transition metals in an acid solution ${ }^{2), 3)}$. Further, softness of the transition metal as the acid has been found to change in the order of $\mathrm{V}<\mathrm{Cr}<\mathrm{Fe}<\mathrm{Co}<\mathrm{Ni}>\mathrm{Cu}<\mathrm{Zn}^{3), 4)}$. A backcoordination of metal electrons to a vacant dorbital of the polar atom has been suggested to occur in the soft base-soft acid interaction ${ }^{3) \sim 5)}$.

* 3-14-1, Hiyoshi, Kohoku-ku, Yokohama, 223 Japan
According to the concept of the HSAB principle, polar atoms or ions of hard acids and bases hold valency electrons tightly and those of soft acids and bases hold loosely. The soft acids prefer to bind to the soft bases, and the hard acids prefer to bind to the hard bases, forming stable complex bonds. The stable acid-base complexes form hardly in the other interactions. Because a bulk metal is a soft acid, in general, a soft base can easily chemisorb on the metal in corrosion medium where all species are hard acids or bases. A compound acting as the softer base is thus a more effective inhibitor.

The compounds, in which elements of the polar atoms belong to the $4 \mathrm{~B}, 6 \mathrm{~B}$, and $7 \mathrm{~B}$ groups of the periodic table, were used as the corrosion inhibitors in this work. The inhibition efficiencies of the inhibitors were determined on non-transition metals, $\mathrm{Mg}, \mathrm{Al}, \mathrm{In}$, and $\mathrm{Sn}$ in $\mathrm{HClO}_{4}$ solutions by polarization measurements, and discussed in relation to the HSAB principle. The acid softness of these metals was evaluated on the basis of this relation and compared with those of the transition metals.

\section{Experimental}

\subsection{Corrosion inhibitors}

The inhibitors used were $\mathrm{RC} 1, \mathrm{RBr}, \mathrm{RI}, \mathrm{R}_{2} \mathrm{O}$, 
$\mathrm{R}_{2} \mathrm{~S}, \mathrm{R}_{2} \mathrm{Se}, \mathrm{R}_{2} \mathrm{Te}, \mathrm{RC}\left(\mathrm{CH}_{3}\right)_{3}, \mathrm{R}_{4} \mathrm{Si}, \mathrm{R}_{4} \mathrm{Ge}$, and $\mathrm{R}_{4} \mathrm{Sn}$. All of the alkyl groups in the inhibitors were n-propyl groups. The term, 7B group inhibitor, for example, was used for that of which the polar atom is of the $7 \mathrm{~B}$ group in the periodic table as was $\mathrm{RC} 1, \mathrm{RBr}$, and $\mathrm{RI}$.

Di-n-propyl selenide and telluride were synthesized by the reaction of Se and Te with n-propyl bromide in a formaldehyde-sodium sulfoxylate solution. Tetra-n-propylsilane, germane, and tin, and also 2,2-dimethylpentane were derived from $\mathrm{SiCl}_{4}, \mathrm{GeCl}_{4}, \mathrm{SnCl}_{4}$, and $\left(\mathrm{CH}_{3}\right)_{3} \mathrm{CBr}$. by Grignard reaction. Other inhibitors were obtained as highgrade commercial reagents. All the inhibitors were carefully pruified by distillation before use. Some compounds were kept under $\mathrm{N}_{2}$ gas not to be in contact with air because of susceptibility to oxidation.

The inhibitor was dissolved in a $3.0 \mathrm{M}$ or $0.30 \mathrm{M}$ $\mathrm{HClO}_{4}$ solution which was prepared by diluting reagent-grade $\mathrm{HClO}_{4}$ with redistilled water. Since some of the 4B group inhibitors were insoluble in the acid solution, $6 \mathrm{wt} \%$ of methanol was added for dissolving them in the solution.

\subsection{Metals}

Metals used in this experiment were $99.9 \% \mathrm{Mg}$ (impurities: $\mathrm{Mn}, 0.01 \%$; $\mathrm{Si}, 0.01 \%$; $\mathrm{Fe}, 0.007 \%$; $\mathrm{Pb}, 0.005 \%$; $\mathrm{Cu}, 0.005 \%$; Ni, $0.001 \%$; Sn, $0.001 \%$, $99.99 \% \mathrm{Al}(\mathrm{Si}, 0.0008 \%$; $\mathrm{Fe}, 0.0006 \% ; \mathrm{Mg}$, $0.0002 \%$; Ca, $0.0001 \%$ ), $99.99 \%$ In (Cd, $0.0007 \%$; $\mathrm{Pb}, 0.0001 \%$; Sn, $0.0001 \%), 99.99 \% \mathrm{Sn}(\mathrm{Pb}$, $0.0003 \%$; Bi, $0.0001 \%$; Mg, $0.0001 \%$ ), and $99.99 \%$ $\mathrm{Fe}(\mathrm{Ca}, 0.0003 \%$; $\mathrm{Mg}, 0.0002 \%$; Cr, $0.0001 \%$; $\mathrm{Cu}, 0.0001 \%$; Si, $0.0001 \%$ ).

The metal rod of 5 or $6 \mathrm{~mm}$ diameter was embedded in a Teflon rod and abraded with No. 2,000 emery paper. The electrode was etched before the polarization measurement; the $\mathrm{Mg}$ electrode was immersed in $0.30 \mathrm{M} \mathrm{HClO}_{4}$ for $30 \mathrm{~s}$ at a room temperature, $\mathrm{In}, \mathrm{Sn}$, and $\mathrm{Fe}$ in $3.0 \mathrm{M}$ $\mathrm{HClO}_{4}$ for $60 \mathrm{~s}$ at $50^{\circ} \mathrm{C}$, and $\mathrm{Al}$ in an $\mathrm{H}_{3} \mathrm{PO}_{4}^{-}$ $\mathrm{HNO}_{3}$ solution at $120^{\circ} \mathrm{C}$ for $10 \mathrm{~s}$.

\subsection{Polarization measurements}

A glass cell equipped with a Pt counter electrode and a reference electrode (SCE) was used in the measurements. The test electrode was vertically immersed in the $\mathrm{HClO}_{4}$ solution. Since dissolution of $\mathrm{Mg}$ was drastic in $3.0 \mathrm{M} \mathrm{HClO}_{4}$, the $0.30 \mathrm{M}$ $\mathrm{HClO}_{4}$ solution was adopted for the polarization measurement of $\mathrm{Mg}$ electrode. The acid solutions were deaerated by passing nitrogen gas. Temperature of the solution was kept at $30 \pm 0.1^{\circ} \mathrm{C}$.

Polarization was carried out potentiostatically.
Several runs were made, both with and without the inhibitor in the solution at each of the concentration.

\section{Results}

The polarization curves showed that most of the $6 \mathrm{~B}$ and $7 \mathrm{~B}$ group inhibitors inhibited both the cathodic, hydrogen evolution reaction and the anodic, metal dissolution reaction. Good reproducibility of the cathodic polarization curve was not obtained for the $\mathrm{Sn}$ electrode inhibited with the $\mathrm{S}, \mathrm{Se}$, and $\mathrm{Te}$ compounds and moreover, even stimulation of the cathodic reaction was observed. Although the polarization curves showed the inhibition of anodic reaction, data for the $\mathrm{Sn}$ electrode with the $6 \mathrm{~B}$ group inhibitors were excluded from the discussion.

The 4B group inhibitors except the carbon compound inhibited the cathodic reaction but were ineffective for the anodic reaction of these metals. This result agreed with that of the transition metals $^{5}$. $\mathrm{RC}\left(\mathrm{CH}_{3}\right)_{3}$ was adopted in the experiment instead of $\mathrm{R}_{4} \mathrm{C}$. Because of no inhibition effect of this compound, $\mathrm{R}_{4} \mathrm{C}$ was estimated to be ineffective in the range of the concentration tested.

Corrosion current density was obtained by the intersection of extrapolated anodic and cathodic Tafel lines. Inhibition efficiency, $I$ was defined

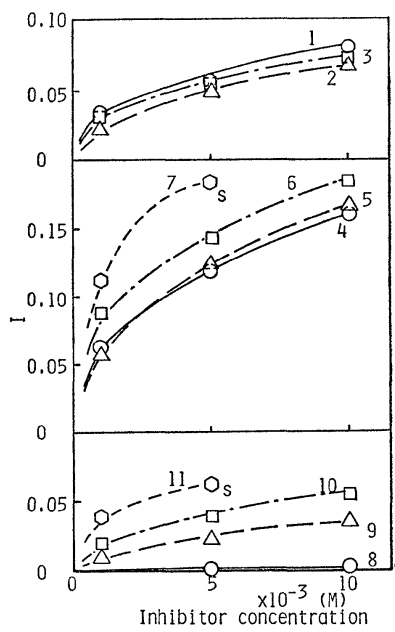

Fig. 1 Inhibition efficiency, $I$ of the 7B, 6B, and 4B group inhibitors for $\mathrm{Mg}$ in $0.30 \mathrm{M}$ $\mathrm{HClO}_{4}$.

1, RCl; 2, RBr; 3, RI; 4, $\mathrm{R}_{2} \mathrm{O} ; 5, \mathrm{R}_{2} \mathrm{~S} ; 6$, $\mathrm{R}_{2} \mathrm{Se} ; 7, \mathrm{R}_{2} \mathrm{Te} ; 8, \mathrm{RC}_{\left(\mathrm{CH}_{3}\right)_{3} ; 9, \mathrm{R}} \mathrm{Si} ; 10$, $\mathrm{R}_{4} \mathrm{Ge} ; 11, \mathrm{R}_{4} \mathrm{Sn}$.

s: saturated in the solution. 


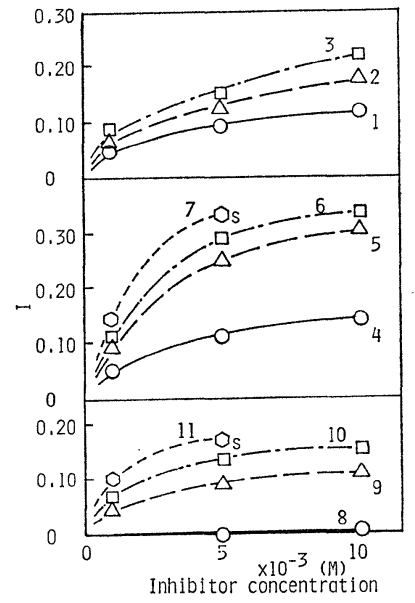

Fig. 2 Inhibition efficiency, $I$ of the 7B, 6B, and 4B group inhibitors for In in $3.0 \mathrm{M} \mathrm{HClO}_{4}$. 1, RCl; 2, RBr; 3, RI; 4, $\mathrm{R}_{2} \mathrm{O} ; 5, \mathrm{R}_{2} \mathrm{~S}$; $6, \mathrm{R}_{2} \mathrm{Se} ; 7, \mathrm{R}_{2} \mathrm{Te} ; 8, \mathrm{RC}\left(\mathrm{CH}_{3}\right)_{3} ; 9, \mathrm{R}_{4} \mathrm{Si} ; 10$, $\mathrm{R}_{4} \mathrm{Ge} ; 11, \mathbf{R}_{4} \mathrm{Sn}$.

$\mathrm{s}$ : saturated in the solution.

by Eq. (1),

$$
I=1-i_{\text {corr }} / i_{\text {corr }}^{0}
$$

where $i_{\text {corr }}$ and $i_{\text {corr }}^{0}$ are the corrosion current densities for the inhibited and uninhibited electrodes, respectively. Fig. 1 shows the inhibition efficiency of the 4B, 6B, and 7B group inhibitors for the corrosion of $\mathrm{Mg}$ in $0.30 \mathrm{M} \mathrm{HClO}_{4}$. The values of these inhibitors for In in $3.0 \mathrm{M} \mathrm{HClO}_{4}$ were also plotted in Fig. 2.

The efficiency of the inhibitors for the corrosion of the transition metals has been reported in the previous papers ${ }^{3), 4)}$ to increase in the orders, $\mathrm{RC} 1<\mathrm{RBr}<\mathrm{RI}, \quad \mathrm{R}_{2} \mathrm{O}<\mathrm{R}_{2} \mathrm{~S}<\mathrm{R}_{2} \mathrm{Se}<\mathrm{R}_{2} \mathrm{Te}$, and $\mathrm{RC}\left(\mathrm{CH}_{3}\right)_{3}<\mathrm{R}_{4} \mathrm{Si}<\mathrm{R}_{4} \mathrm{Ge}<\mathrm{R}_{4} \mathrm{Sn}$. In many cases, the orders of the efficiency agreed with the above for the metals examined. But the order of the 7B group inhibitors was $\mathrm{RC} 1<\mathrm{RBr}>\mathrm{RI}$ for the $\mathrm{Mg}$ and $\mathrm{Al}$ electrode.

\section{Discussion}

The inhibition efficiency of the polar organic compound depends mainly on an ability of adsorption, an area of the metallic surface effectively covered by an adsorbed molecule, and a steric hindrance to the adsorption. Size of nonpolar groups in the compound affects the effectively covered area. Since all of the nonpolar groups are n-propyl, the effect of the area on the efficiency was taken to be constant in a each group of the inhibitors. There seems no steric hindrance of n-propyl groups to the chemisorption of the inhibitor $^{6}$. Therefore, the value of $I$ depends mainly on the ability of adsorption which is closely related to the HSAB principle.

It is considered that the polar organic molecules adsorb on the metallic surface by means of three types of the interactions between the polar atom and the metal, (1) an electrostatic, (2) a covalent, and (3) a $\pi$-bonding interaction. The electrostatic and covalent interaction are associated with the hard acid-hard base and soft acid-soft base attraction, respectively. The $\pi$-bonding interaction relates to back-donation of the metal electrons to an unoccupied orbital of the polar atom. The adsorption of the 4B group inhibitors, of which polar atoms hold no pair of unshared electrons, is attributed to the back-donation. However, effect of the $\pi$-bonding interaction on the inhibition efficiency was estimated to be relatively low as compared with the effect of the other interactions, since the values of $I$ of the 4B group inhibitors were far lower than those of the $6 \mathrm{~B}$ group inhibitors. It was thus assumed that the effect of back-donation was not important to the inhibition efficiency of the $6 \mathrm{~B}$ and $7 \mathrm{~B}$ group inhibitors.

According to the linear free energy relationship, the efficiency is expressed as

$$
\log (I / 1-I)=\rho^{\prime} \chi+\alpha^{\prime}
$$

where $\chi$ is the electronegativeity of the polar atom in the inhibitor, and $\rho^{\prime}$ and $\alpha^{\prime}$ are constants, respectively $^{3)}$. The values of $\log (I / 1-I)$ for $\mathrm{Mg}^{\prime}$ Al, In, and Sn were plotted against $\chi$ in Fig. 3 to 6 , respectively. The electronegativity is a measure of softness of the polar atom as a base. For the transition metals examined in the previous papers ${ }^{3), 4}$, linear correlations have been

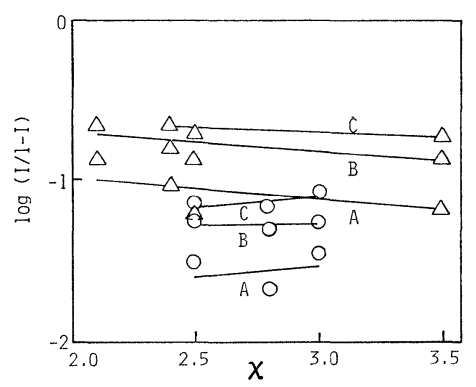

Fig. 3 Relationship between $\log (I / 1-I)$ and electronegativity, $\chi$ for the $\mathrm{Mg}$ electrode inhibited with the $7 \mathrm{~B}(\mathrm{O})$ and $6 \mathrm{~B}(\triangle)$ group inhibitors.

$\mathrm{A}$, at $1 \times 10^{-3} \mathrm{M} ; \mathrm{B}$, at $5 \times 10^{-3} \mathrm{M} ; \mathrm{C}$, at $1 \times 10^{-2} \mathrm{M}$ of the inhibitor concentration. 


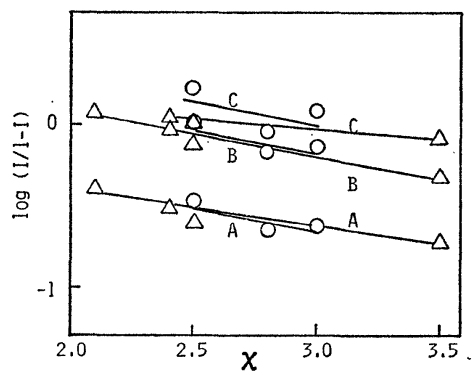

Fig. 4 Relationship between $\log (I / 1-I)$ and electronegativity, $\chi$ for the $\mathrm{Al}$ electrode inhibited with the 7B $(O)$ and $6 \mathrm{~B}(\triangle)$ group inhibitors.

$\mathrm{A}$, at $1 \times 10^{-3} \mathrm{M} ; \mathrm{B}$, at $5 \times 10^{-3} \mathrm{M}$; C, at $1 \times 10^{-2} \mathrm{M}$ of the inhibitor concentration.

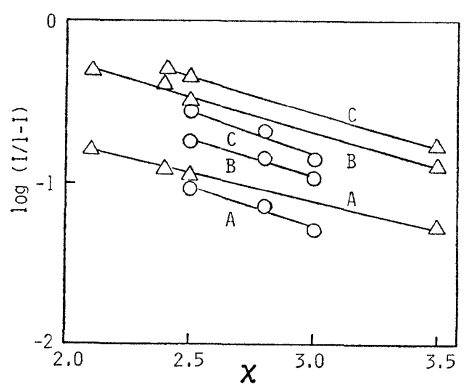

Fig.'5 Relationship between $\log (I / 1-I)$ and electronegativity, $\chi$ for the In electrode inhibited with the 7B $(O)$ and $6 \mathrm{~B}(\triangle)$ group inhibitors.

$\mathrm{A}$, at $1 \times 10^{-3} \mathrm{M} ; \mathrm{B}$, at $5 \times 10^{-3} \mathrm{M} ; \mathrm{C}$, at $1 \times 10^{-2} \mathrm{M}$ of the inhibitor concentration.

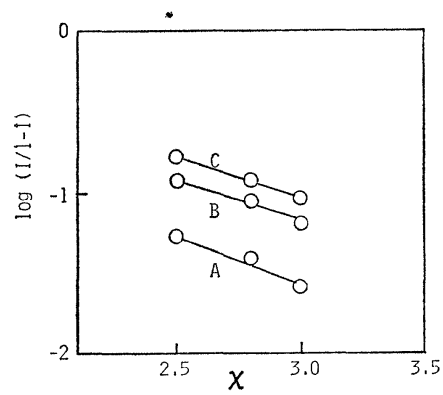

Fig. 6 Relationship between $\log (I / 1-I)$ and electronegativity, $\chi$ for the Sn electrode inhibited with the 7B group inhibitors.

$\mathrm{A}$, at $1 \times 10^{-3} \mathrm{M}$; B, at $5 \times 10^{-3} \mathrm{M} ; \mathrm{C}$, at $1 \times 10^{-2} \mathrm{M}$ of the inhibitor concentration.

obtained between $\log (I / 1-I)$ and $\chi$ of the $6 \mathrm{~B}$ and 7B group inhibitors. The figures show that the linear relationship between them was also established for the non-transition metals. This rela-
Table 1 The average values of $-\rho^{\prime}$.

\begin{tabular}{lcc}
\hline Metal & \multicolumn{2}{c}{$-\rho^{\prime}$} \\
\cline { 2 - 3 } & $7 \mathrm{~B}$ group inhibitors & $6 \mathrm{~B}$ aroup inhibitors \\
\hline Mg & -0.09 & 0.09 \\
$\mathrm{Al}$ & 0.27 & 0.20 \\
$\mathrm{In}$ & 0.49 & 0.41 \\
$\mathrm{Sn}$ & 0.57 & - \\
\hline
\end{tabular}

tionship was, however, not necessarily valid for $\mathrm{Mg}$ and $\mathrm{Al}$ inhibited with the 7B group inhibitors as shown in Fig. 3 and 4 . This inconsistency is attributed to a lack of acid softness of these metals.

On the assumption that the relationship expressed by Eq. (2) is valid for the examined metals, a slope of the straight line, $\rho^{\prime}$ was determined in the figure. The slopes were almost constant for each group of the inhibitors at the different concentrations. This result is reasonable because the Hammett-like equation such as Eq. (2) is independent of the concentration of the inhibitor. The average values of $-\rho^{\prime}$ were listed in Table 1 for the metals inhibited with the $6 \mathrm{~B}$ and $7 \mathrm{~B}$ group inhibitors.

The inhibition efficiency for the corrosion of $\mathrm{Mg}$ was measured in $0.30 \mathrm{M} \mathrm{HClO}_{4}$ while the efficiency for the other metals in $3.0 \mathrm{M} \mathrm{HClO}_{4}$. In order to verify no difference in $-\rho^{\prime}$ between $0.30 \mathrm{M}$ and $3.0 \mathrm{M} \mathrm{HClO}_{4}$, the author determined the inhibition efficiency of the $6 \mathrm{~B}$ and $7 \mathrm{~B}$ group inhibitors for the $\mathrm{Fe}$ electrode in the $0.30 \mathrm{M}$ and $3.0 \mathrm{M} \mathrm{HClO}_{4}$

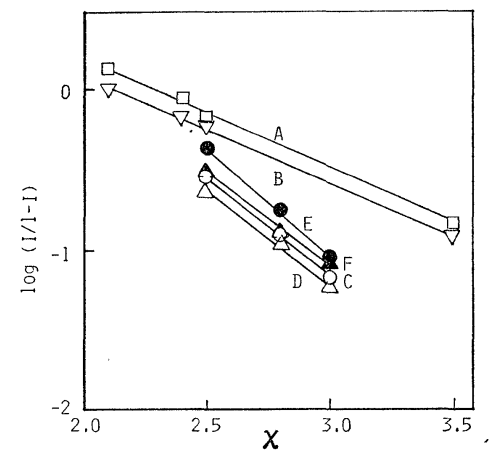

Fig. 7 Relationship between $\log (I / 1-I)$ and $\chi$ for the $\mathrm{Fe}$ electrode inhibited with the $6 \mathrm{~B}$ and $7 \mathrm{~B}$ group inhibitors in the $3.0 \mathrm{M}$ and $0.30 \mathrm{M} \mathrm{HClO}_{4}$ solutions.

$3.0 \mathrm{M} \mathrm{HClO}_{4} \quad 0.30 \mathrm{M} \mathrm{HClO}_{4}$

\begin{tabular}{lll}
\hline 6 B group inhibitors & & \\
at $5 \times 10^{-3} \mathrm{M}$ & A & B \\
7 B group inhibitors & & \\
at $5 \times 10^{-3} \mathrm{M}$ & $\mathrm{C}$ & $\mathrm{D}$ \\
at $1 \times 10^{-2} \mathrm{M}$ & $\mathrm{E}$ & $\mathrm{F}$
\end{tabular}


Table 2 The $-\rho^{\prime}$ values of $\mathrm{Fe}$ determined in $3.0 \mathrm{M}$ and $0.30 \mathrm{M} \mathrm{HClO}_{4}$.

\begin{tabular}{lcc}
\hline & \multicolumn{2}{c}{$-\rho^{\prime}$} \\
\cline { 2 - 3 } & $3.0 \mathrm{M} \mathrm{HClO} 0_{4}$ & $0.30 \mathrm{MClO}_{4}-$ \\
\hline 6B group inhibitors & 0.68 & 0.68 \\
7B group inhibitors & 1.19 & 1.10 \\
\hline
\end{tabular}

solutions at $30^{\circ} \mathrm{C}$. The result was shown in Fig. 7 , indicating that the slopes were almost constant for each group of the inhibitors as shown in Table 2, although the values of $I$ in $0.30 \mathrm{M} \mathrm{HClO}_{4}$ were lower than those in $3.0 \mathrm{M} \mathrm{HClO}_{4}$. The values of $-\rho^{\prime}$ for $\mathrm{Mg}$ in $3.0 \mathrm{M} \mathrm{HClO}_{4}$ were taken to be almost the same as those in $0.30 \mathrm{M} \mathrm{HClO}_{4}$.

According to the relationship between the stability constant of acid-base complex and parameters corresponding to the softness and hardness of acid and base, the value of $-\rho^{\prime}$ denotes a relative softness of the metal as the acid ${ }^{3), 4)}$. The values shown in Table 1 lead to a conclusion that the acid softness of the metals increased in the order of $\mathrm{Mg}<\mathrm{Al}<\mathrm{In}<\mathrm{Sn}$. The values of $-\rho^{\prime}$ for the transition metals were 0.50 to 1.35 for the $7 \mathrm{~B}$ group inhibitors and 0.43 to 0.76 for the $6 \mathrm{~B}$ group inhibitors. The non-transition metals examined in this work seems to be relatively harder acids than the transition metals. Hence, an inhibitor acting as a soft base prefers to chemisorb on the transition metals rather than on the non-transition metals. This may be attributed to the difference in stabilities of acid-base interactions using an $s$ or p-orbital of the the nontransition metal and d-orbital of the transition metal.

Indium was a softer acid than aluminum. This is reasonable because In atom holds valency electrons more loosely than A1. The higher acid softness of In can, in addition, be elucidated by the backdonation of metal electrons to the empty d-orbital of the polar atom, as has been discussed on the transition metals. In fact, the inhibition efficiencies of $\mathrm{R}_{4} \mathrm{Si}, \mathrm{R}_{4} \mathrm{Ge}$, and $\mathrm{R}_{4} \mathrm{Sn}$ for In and $\mathrm{Sn}$ were higher than those for $\mathrm{Mg}$ and Al (Fig. 1 and 2).
Aluminum was a softer acid than $\mathrm{Mg}$ and $\mathrm{Sn}$ was softer than In. The latter order of softness. seems to agree with the order of acid softness, Bi and $\mathrm{Sb}$ being softer than $\mathrm{Ga}$ and $\mathrm{In}^{7), 8)}$. However, these orders of the softness cannot be explained by the looseness of valency electrons. Further experiments of the non-transition metals. are needed for solving the problem.

\section{Conclusion}

The corrosion inhibition efficiencies of the 7B and $6 \mathrm{~B}$ group inhibitors for non-transition metals, $\mathrm{Mg}, \mathrm{Al}, \mathrm{In}$, and $\mathrm{Sn}$ in the $\mathrm{HClO}_{4}$ solutions were found to be closely related to the HSAB principle. The acid softness of the metals was estimated by using this relation. The softness was increased in the order of $\mathrm{Mg}<\mathrm{Al}<\mathrm{In}<\mathrm{Sn}$. The softness values of the non-transition metals were lower than those of transition metals examined in the previous work. The efficiency of the $4 \mathrm{~B}$ group inhibitors suggested the formation of $\pi$-bond by the back-donation of metal electrons to the vacant d-orbital in the polar atom of the inhibitor.

(Received October 5, 1982)

\section{References}

1) R. G. Pearson Ed.: "Hard and Soft Acids and Bases", p. 1, Dowden Hatchinson \& Ross. Inc., Stroudsburg (1973).

2) K. Aramaki, S. Iizumi: Denki-kagaku, 45, 396 (1977).

3) K. Aramaki: "Proceedings 5th European Symposium on Corrosion Inhibitors", vol. 1, p. 267, Universita Degli Studi di Ferrara, Ferrara (1980).

4) K. Aramaki, S. Iizumi \& F. Nakagawa: Boshoku Gijutsu, 29, 566 (1980).

5) K. Aramaki \& S. Iizumi: Denki-kagaku, 46, 573 (1978).

6) K. Aramaki: Boshoku Gijutsu, 26, 297 (1977).

7) T. N. Andersen, J. L. Anderson \& H. Eyring: J. Phys. Chem., 73, 3562 (1969).

8) D. J. Barclay \& J. Čaja: Croatica Chemica Acta, 43, 221 (1971). 